\title{
Research on Female Domestic Cold Violence
}

\author{
Liu Jie \\ School of Marxism \\ Hunan University \\ Changsha, China \\ e-mail:271964410@qq.com
}

\author{
Zhang Jun* \\ School of Marxism \\ Hunan University \\ Changsha, China \\ e-mail:1969595900@qq.com \\ * Corresponding Author
}

Keywords: Female; Family; Domestic cold violence; Harm; Measure

\begin{abstract}
The gradual increase of female domestic cold violence can be attributed to three factors, i.e. historical, personal and social factors. And the destruction and harm of female domestic cold violence to harmonious and stable families should not be underestimated. Therefore, it ought to be prevented and solved by means of guiding awareness, training behavior, improving social security and legal systems so as to lay a solid foundation for building warm and happy families.
\end{abstract}

\section{Introduction}

Family is the basic element of a community, and the amity and happiness of a family is the premise of a harmonious and peaceful country. However, in recent years, as various news media reported, domestic cold violence with women as the implementation subjects has quietly emerged in some families. Domestic cold violence (emotional abuse), together with domestic hot violence (physical abuse) belongs to the category of domestic violence. Different from the illegal behaviors of hot violence such as beating, cruelly killing and limiting personal freedom in [1], domestic cold violence refers to the behaviors such as coldness, neglect, indulging and estrangement that women show to their family members who are in marital, kinship or other legal relationships with them [2]. The nature of it is mental harm to family members, which is hidden in family life and ready to break up family unity and stability like a "bomb". Hence, to study and solve the issue of feminine domestic violence is beneficial to improve people's livelihood and household happiness index.

\section{Characteristics of Female Domestic Cold Violence}

In the studies of female domestic cold violence, men are often regarded as the implementation subjects while women as victims. But the reality is that it is women who mostly attack or treat their partners with verbal attacks or indifference, which is a new characteristic of recent domestic violence in [3]. The domestic cold violence where women act as implementation subjects should also be paid due attention. To solve the issue of female domestic cold violence effectively, one first need to be aware of the characteristics of it.

Distribution: Educated Young People. The female domestic cold violence is mainly seen in young intelligible families. An investigation of 440 cases of domestic violence shows that the perpetrators are mainly aged between $26 \sim 35$, and between $36 \sim 49$. After young people get married, they all step into the period of adaptation of personality and habits to each other. In life, the new wives need to blend in new family, and conflicts will occur between them and their husbands' family members in eating habit and daily routine etc. And after a while, when young couples come back from ideal to the reality, husbands may tend to focus on their work, which may probably considered as "neglect after wedding", "marital deception" or "lack of premarital romance" by young wives, and thus young wives would blame and scold their husbands, even get divorce. Generally, when a young lady from different family background blends into a strange family, she will struggle against other 
family members on whether her life attitude is positive or not, consumption generous or not, and children education right or not. In accordance to some relevant data, about a quarter of families are suffering the female domestic cold violence including $25 \%$ highly educated families in [4].

Behavioral Pattern: Complex and Diversified. In different family environments, female domestic cold violence behaves differently. The wife attacks her husband with bad words, satirizes, stops sexual life and communication, and even disappears for several days or longer; On children education, the wife tends to despise and insult her children due to study performance; Mother-in-law are dissatisfied with, even scold her daughter-in-law for her money abuse and because she cares her own parents too much; Mother-in-law and her daughter-in-law will attack each other for household duties and other corresponding responsibilities and obligations; Mother-in-law may take sides on her son and blame her daughter-in-law when her son has conflicts with his wife and so on; the female demotic cold violence behaves variously, which shows that the family is going to be inharmonious and restless, suffering from various conflicts.

Changing trend: Popularization and Generalization. Female domestic cold violence increasingly emerges in people's daily life. With the dramatic improvement of living standard, it is extending from a family problem to be a social one being urgent to solve. "Chinese women emancipation is the most successful one which equalizes man and woman, even resulting in woman's superiority to man", an American learner once claimed. On October 11th, 2005, "Life's Journey", a CCTV program on marriage suffering from female emotional abuse, made an investigation. The results show that $93 \%$ families are dissatisfied with their marital status, over $70 \%$ families once had or suffered from cold violence to various extents. A British investigation conducted in 2011 demonstrates that over $40 \%$ victims of domestic emotional abuse are men. Data from another investigation, by Chinese law association, on over 3000 Chinese families suffering from emotional abuse, show that about $88 \%$ couples never cared about each other. The analysis of investigation of juvenile delinquency all over the country shows that due to bad school performance or immoral behaviors, $14.9 \%$ children are "frequently" scolded by their mom, $68.3 \%$ "sometimes", only $15.8 \%$ "never" in [5]. Feminine emotional abuse is increasingly killing the harmony of a family.

\section{Reasons Exploration: The Causes of Female Emotional Abuse in Family}

The causes of female emotional abuse in family are complicated and diversified. In order to analyze those causes correctly, the inner occurrence mechanism should be studied first objectively and comprehensively.

Historical Factor: the Traditional View. Women as wives. When some women encounter little things, they cannot bear and just take a strategy of "crying, fighting and hanging". They intend to give psychological blow to their husbands by means of insulting, ridiculing, divorcing and threatening. And when some get in conflicts with their husbands, they would start a long-term cold war and refuse to have sexual life with their spouses. Consequently, their husbands feel discontent physiologically and upset psychologically. Then void, stress, loneliness and even despair will follow. Since ancient times, the view "Do not wash your dirty linen in public" has been widespread in China, which advocates that domestic problems should be solved within the family. For being lack of public opinion condemnation, the harm of emotional abuse in family will be covered and the solution of the problem is postponed. For women are usually implicit, they won't admit their faults even they know they are wrong, and they will wait for their husbands' apologies. This satisfies their vanity, but hurts their husband's dignity.

Women as mothers. Since ancient times, every Chinese parent has wished their sons and daughters a bright future. In this competitive society, no mother likes her children to lose at the starting line. They keep forcing their children to study, comparing them with others, and regarding the academic record as the only standard to assess children's success. If their children get bad grades, they will seriously criticize, condemn and even kick them out of home. As a result, their children's grades keep 
slipping and the worst is that sometime they may behave like schizophrene and commit suicide. That would be too late to change.

Women as daughters. Dan Shanya, a Japanese lawyer, said, "if anyone can figure out a witty way to handle the relationship between mother-in-law and daughter-in-law, he or she should be awarded the Nobel Prize." Most people hold the view that such relationship can't be handled well, which therefore will leads to negative effect to women when they have to confront it. Then, it would be harder to find a solution because of its behavior characteristics which includes weak emotional foundation, dislocation of expecting role, jealousy between mother-in-law and daughter-in-law and female natures [6].

Personal Factor: Physiological Troubles. Relatively speaking, the female is disadvantaged in the physical strength and ability. Therefore, they often take verbal attacks or cold war in conflicts. To get psychological balance, women take the weakness of family members as an entry point to attack them, which in reality hurts their self-esteem and undermines their relationship.

With special physiological structure influenced by hormones, women are likely to have emotional problems in some unique stages, from menstruation, pregnancy to menopause. A psychologist made retrospectively analysis of 96 women aged between 17 45, investigating the relationship between the female mood disorders and menstrual cycle. Results show that of the 85 women with menstruation, 34 have emotional problems (accounting for 40\%) in [7]. Therefore, female emotional disorder is closely related to women's menstrual cycle. In the menstruation period, women may properly low in mood, and any setbacks or spiritual stimulation are likely to lead to their extreme behaviors. When they are irritable or depressed, even small conflicts will trigger domestic cold violence, which will probably evolve into family conflict.

Social factor: Troubles from Daily Life. Compared with traditional wives, most wives in modern families are in charge of the family finance. Therefore, the husbands have to report their expenses on social communications and other entertainment activities. It is obviously that husbands have lost proper rights in family and personality and dignity in front of friends. With changes of people's concept of life, the marriage combination has changed from "making arrangement by parents" to "free love." At the same time of enjoying the happiness of freedom in love, the temptation of finance, real estate and other interests often lead to marital tension. It undoubtedly sows the seeds of the female family cold violence. Family life is closely linked with the real society, and it will produce numerous unexpected contradictions, most of which will become fuse of female domestic violence. Meanwhile, with the increase of life pressure, some vainglorious wives often chatter to their husbands about family economic problems. Women express dissatisfaction by means of indifference or refusing sexual life. Van women may also compare their husbands with others. Some husbands are often criticized and given a hard time once behind the others. Some couples quarrel for the educating children, and always put children's ranking in class as on their mind. Children bear pressures not only from teacher and study at school, but also from their parents at home. In complex family relationship, the stepmother deprives children of education. These may upgrade the female cold violence in the family.

Of course, there are other reasons caused cold violence. On the one hand, this violence cannot be identified in law. There is a not yet specific legal provision that indicates what kind of compensation or punishment should be applied to women. This is one of the reasons why the female family cold violence continues to heat up. On the other hand, this violence is invisible for the harm done by this kind of violence is spiritual instead of physical. And women are lack of deep understanding of this type of cold violence, unaware of its potential harm to the family and their children.

\section{Harm: the destructive power}

The female domestic cold violence hidden in family life would bring about serious consequences if it is not detected and solved timely. To be specific, it will do following harms. 
Harm to Women Themselves. Generally, female domestic cold violence will not only hurt the family members but also women themselves, that is, at the same time of destroying the harmony of the family, women may get into deep sorrow themselves. When they are angry over small conflicts, they are damaging their own health and spirit. Traditional Chinese Medicine (TCM) theory holds that being angry will affect the temper, lead to mood fluctuations. Some people love sulking, which is greatly harmful. Being angry especially hurtful to breasts and uterus.

Harm to the Family. The female cold violence will bring about spiritual damage to family members and widen the psychological distance with them. Spiritual damage will lead to disappointment, pain, low self-esteem, depression, schizophrenia, and even suicide. It is reported that about $50 \%$ patients with depression have suicidal thoughts, and more than $70 \%$ families ever had or are in different levels of emotional abuse in [8]. Thus, to some extent, female family cold violence is more lethal than the domestic hot violence. It is known to all that physical harm can be healed, but the damage of the soul is too hard to recover.

Moreover, it can viciously cycle, and therefore, will result in continuous family tensions. After being misunderstood and hurt outside, sometimes, the family members also have to suffer from female family cold violence at home, which make them almost collapse. Some men cannot get expected comforting and satisfaction at home, so they will try to have an extramarital affair with another woman, which may bring disaster to their marriage. Meanwhile, home is the warm haven to everyone. Creating family atmosphere with love is a necessary prerequisite for children's psychological growth. Female cold violence is likely to cause psychological distortions of children, such as self-absesement and autism. And this cold violence has subtle influence on children's behavior. Once the child imitates his or her mother and thinks it's reasonable, their development will be greatly affected. The conflict between the mother-in-law and daughter-in-law also will put the family in instability. A statistic from the People's Court of a city shows that the proportion of divorce caused by bad relationship between the mother-in-law and daughter-in-law in the family is $7 \%$. And the rate is on an increase each year [9]. This phenomenon is prevalent in China. A large number of families in cold violence are troubled by family disintegration.

Harm to the Society. Like other forms of family violence, the female cold violence is not only a private matter but also a social one. It is one of the important reasons contributed to the rise of divorce rate these years. Some men even loss joy of living and take the bad mood to the work for their wives' coldness and indifference, which greatly affects their life quality and working efficiency. Some men, on the contrary, take hot violence to resolve the cold violence because they can't stand any more, which lead to bloodshed, vicious criminal sometimes. As for children, when they are faced with cold violence, they feel no warmth at home, so they may be addicted to computer games or even gradually commit crimes [10].

\section{Solution: prevention and countermeasures}

How to solve the problem of female domestic cold violence and make various factors come into play is a pressing problem for each family and relevant authority.

Awareness Guidance: Raise Women's Awareness of Female Domestic Cold Violence. Women should realize that the victims of the cold violence suffer from great torture psychologically and mentally, and the abuser is more prone to feel depressed and anxious with time goes by. The education level of women is an important factor for a happy family. It is their duty to give more attention and love to the family members. It is also helpful to find factors of inharmonious situations in family and solve them immediately. Women are wished to learn from model families. They also should learn to detect merits of their husbands, parents and children with a tolerant attitude so as to deal with little frictions among family members actively and fulfill their own responsibility in building a happy family. It is generally understood that the improvement of their social status does not 
mean they are allowed to lord over others. At all times, women must remember the traditional virtues of Chinese women.

Behavior Training: Learn to Communicate Effectively. A warm and harmonious family is based on mutual communication and understanding of family members. Communication is a bridge to establish better family relationship. Good communication is a skill to create good family atmosphere. The couple must trust each other, and communicate with each other about conflicts; at the same time, the family members should learn to understand each other. Establish the couple communication principles of "mutual love, mutual respect, mutual encouragement, mutual comfort, mutual accommodation, mutual understanding, mutual aid and mutual learning." We all know that few communications and attentions will cause endless misunderstanding. When misunderstanding accumulates to a certain extent, the couple is even more reluctant to communicate with each other. As a result, the conflicts will go into a vicious cycle, developing from bad to worse. Therefore, anytime when disagreement occurs, the couple should try to understand each other and fight to make the first step towards reconciliation, avoiding deterioration of the situation. Young couples can eliminate misunderstanding by means of shaking hands, hugging and talk. If some women refuse to communicate flatly, writing a letter or note maybe a better way to communicate.

Social Security: Establish Social Assistance System. To establish corresponding social assistance could be a responsibility that the society is required to fulfill to help solve this domestic violence issue. Women's Federation, neighborhood and street administration office can give professional lectures to popularize the new "marriage law" and related legal knowledge. For the families with higher frequency of female cold violence, they can seek help and guidance from the professional. Especially the children from these families should be kept a watchful eye on and taught to identify female family cold violence and the methods and measures to mitigate it. In 2007, the Ministry of Human Resources and Social Security approved the new occupation "Marriage and family counselor." This provides the policy support for the establishment of complaint hotline in community against the cold abuse, which can ensure that the suffering of the victim can appeal. In addition, the hospital system could add some mediation stations for cold violence. Other social departments add the complaints departments. These sectors can serve family suffering from the female domestic cold violence with psychological counseling and targeted advices.

System: Establish a Legal System. In 2010, the French government drew up a law draft, banning family from "psychological violence". This is the first time worldwide that the family violence was raised in the form of law. China also values the legal regulation against family cold violence. At the NPC and CPPCC sessions in 2013, Chinese People's Political Consultative Conference (CPPCC) member and vice chairman of the Women's Federation Zhen Yan submitted motion to establish "antidomestic violence law", with the proposals to accompany this motion. On November 25, 2014, the Legislative Affairs Office of State Council issued the "People's Republic of China Anti-Domestic Violence Law (Exposure draft)", which confirmed the special protection principle for the victims. China should improve the legislation areas of anti-domestic violence law, and develop specific female domestic abuse legal compensation regulations. It could define clearly the specific acts of the female domestic cold violence in the form of law. As a starting point, legal assistance is a valuable method for solving the female domestic cold violence effectively.

\section{References}

[1] The law database of National People's Congress. The Marriage Law of People's Republic of China (revised)[EB/OL]. hppt//www.gov.cn, 2015-04-20.

[2] Yang Ying, Ma Jianqing. The Characteristics of Domestic Cold Violence and its Causal Analysis [J]. Social Sciences Journal of Colleges of Shanxi, 2007, 19(2): 72-75. 
[3] Cui Yi, Hong Wei, Su Ying, et al. A Current Situation Survey and Influential Factors of Domestic Violence in Seven Provinces and Cities of China [J]. Chinese Journal of Clinical Psychology, 2012, 20(3): 360-362, 327.

[4] Yang Genqiao. Status Quo and Roots of Family Violence and Its Countermeasures [J]. Journal of Hefei University (SocialSciences), 2008, 25(6): 19-23.

[5] Guan Ying. Harm of Family Violence to Children and Its Social Intervention [J].Contemporary Youth Research, 2006, (5): 22-27.

[6] Liu Jianfeng. On the Causes of China's Relationship between Mother-in-law and Daughter-in-law in a Multidimensional Perspective [J]. Journal of Shandong Women's University, 2013, 111(5): 57-60.

[7] Liu Jianqiong. Research on correlation of women's mood disorders and menstrual cycle [J]. Chinese Community Doctors, 2010, 12(13): 80-81.

[8] Zeng Zhaoxiang, Liu Lin, Fang Maosheng, et al. The Effect of the Domestic Violence on Suicide in Patients with Depression [J]. Chinese General Practice, 2004, 7(21): 1576-1577.

[9] Zou Xin, Mei Yonghan, Wu Yanhong. Causes of the Conflict between Mother and Daughter-inlaw: Using a Mixed-Methods Analysis Integrating Qualitative and Quantitative Approach [J]. Acta Scientiarum Naturalium Universitatis Pekinensis, 2015, 51(1): 187-194.

[10] Kaixuan Counseling Center. Family Abuse and Emotional Imbalance [M]. Beijing: Foreign Languages Press, 2012: 111-114, 137-142. 